\title{
Malaria treatment-seeking behaviour and related factors of Wa ethnic minority in Myanmar: a cross-sectional study
}

\author{
Jian-Wei Xu ${ }^{1 *}$, Qi-Zhang $X u^{2}$, Hui Liu ${ }^{1}$ and Yi-Rou Zeng ${ }^{3}$
}

\begin{abstract}
Background: In Southeast Asia, data on malaria treatment-seeking behaviours and related affecting factors are rare. The population of the Wa ethnic in Myanmar has difficulty in accessing formal health care. To understand malaria treatment-seeking behaviour and household-affecting factors of the Wa people, a cross-sectional study carried out in Shan Special Region II, Myanmar.

Methods: The two methods, questionnaire-based household surveys to household heads and in-depth interviews to key informants, were carried out independently. The proportion of treatment-seeking patterns was calculated. Logistic regression was used to determine affecting factors of treatment-seeking. Qualitative data were analysed by using Text Analysis Markup System.

Results: Overall, $87.5 \%$ of the febrile population sought treatment, but only $32.0 \%$ did so within 24 hours. The proportion accessing the retail sector $(79.6 \%)$ was statistically significant higher $(P<0.0001)$ than accessing the public sector (10.6\%). Multivariable logistic regression analysis identified family income, distances from a health facility, family decision and patient characteristics being independently associated with delayed malaria treatment.

Conclusion: Malaria treatment-seeking behaviour is not appropriate, and affecting factors include health service systems, social and cultural factors in Wa State of Myanmar.
\end{abstract}

Keywords: Malaria, Treatment-seeking behaviour, Wa ethnic, Household survey

\section{Background}

There were an estimated 216 million episodes of malaria and 655,000 malaria deaths worldwide in 2010 [1]. Malaria is a major cause of poverty and slows economic growth by up to $1.3 \%$ per year in endemic countries [2]. Early diagnosis and effective treatment of all malaria cases is an essential component to reduce the burden of malaria. This requires appropriate infrastructure and resource, and also active engagement and participation of communities [3]. Data on malaria treatment-seeking behaviours and household-affecting factors are rare in Southeast Asia [4,5]. The Wa ethnic minority lives across the China-Myanmar border and its total population is around 1.2 million (740,000 in Myanmar side, and 460,000 in China) [6]. Malaria control among the

\footnotetext{
*Correspondence: xjw426@163.com

'Yunan Institute of Parasitic Diseases, Puer 665000, China

Full list of author information is available at the end of the article
}

population of ethnic minorities is being challenged by treatment-seeking behaviours and accessibility to health service [6]. In Myanmar, Wa people mainly live in Shan Special Region II (locally called Wa State or UWSA territory). Malaria is one of the major public health problems among the population. An active detection found $60 \%(270 / 453)$ of parasite rates among febrile patients and of them $90.74 \%(245 / 270)$ was Plasmodium falciparum [7]. In Wa State, most residents have difficulty in accessing formal health care. Data and information concerning malaria treatment for them are insufficient. This investigation could assist in understanding treatmentseeking behaviour and related household factors.

\section{Methods}

Study area and period

A cross-sectional study was conducted between 1 October and 31 December 2009 in Gelongba and Mandong

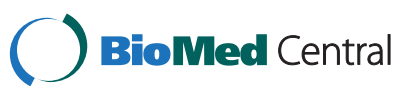




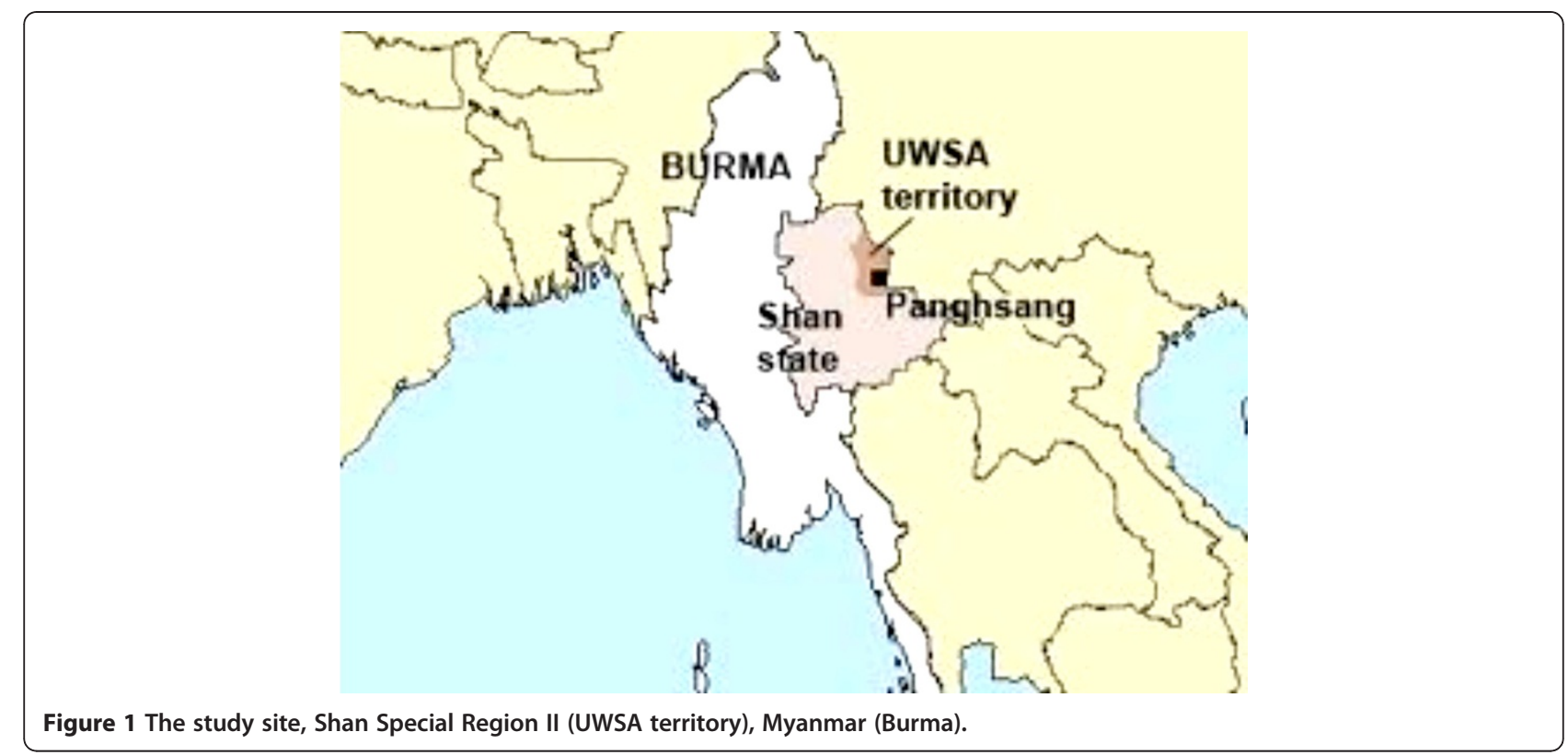

districts, Mengmao County, Wa State (Figure 1). The two districts in Salween River Valley were purposely selected based on their malaria endemicity and prevalence. This area experiences year-round malaria transmission with a peak during the rainy season from September to November. Health care is provided by a community health centre, two NGO health posts by Aide Medical International (AMI) and two private clinics. Drugs are provided by two drug shops and market stalls. All these facilities of health care and pharmacy are located the two main villages: Gelongba and Mandong.

\section{Household survey design and implementation}

The study population included people who had signs/symptoms of malaria in the previous two weeks. The investigation was carried out by household survey (HHS) as a quantitative method and semi-structured in-depth interviews (SDI) to key informants as the qualitative $[8,9]$.

The data collection tools (questionnaires and interview guidelines) were developed in Chinese because Wa language is only a speaking language. One of researchers who can understand both Wa and Chinese Language conducted the interviews in Wa language and then filled out the questionnaires in Chinese. The sampling frame for the survey covered all 64 villages of the districts of Gelongba and Mandong, which have an approximate total population of 18,940 . Households were the units of sampling. A sample size of 350 households was required by using desired $5 \%$ of precision, estimated $35 \%$ of febrile patients in the previous two weeks who sought treatment within 24 hours and $95 \%$ of confidence limits. A household was defined as all those eating from the same cooking pot. Sampling of households was restricted to those with a fever patient in the previous two weeks.

The survey started from Gelongba, one of two main villages. The first household was randomly selected. The researchers visited the subjects village by village and house by house. A household with a fever patient in the previous two weeks was selected for the survey, until the desired sample size was reached. The household head was selected on behalf of the entire household to answer the questionnaires. The questionnaire included structured questions on respondent and household characteristics, details of the treatment-seeking behaviours and malaria-related knowledge $[10,11]$. In order to reduce recall bias, households without fever in the last two weeks were just interviewed for socio-demographic characteristics but for treatment-seeking and other related factors. Details of the youngest one were collected if there was more than one person who had had fever in a household in last two weeks.

To collect information in detail for exploring malaria treatment-seeking, the SDIs were conducted in the same villages sampled for HHS. According to the recommendation of household heads, 23 village heads and 13 village health workers were selected as key informants for interview. The issues discussed with key informants were local health service, people's perception of malaria, treatment-seeking behaviours and related socioeconomic status [12].

All health facilities were visited and their staffs were interviewed on health service in the two districts. An outlet survey of anti-malarial drugs was also conducted and the survey included interviewing medical sellers on their knowledge of drugs. 


\section{Data analysis}

Both quantitative and qualitative data analysis was carried out by two senior researchers (J-W \& H L). Quantitative Data were first checked manually for completeness and then double-entered and validated in EpiData version 3.1 [13]. Epi Info 2000 was used for data processing and analysis. Bivariate analysis between dependent and independent variables was performed using binary logistic regression. To control the effect of confounding variables, multivariate logistic regressions were done. Adjusted OR and 95\% CI were used to interpret the findings. Qualitative data were analysed by using Text Analysis Markup System (TAMS). The data were encoded on the basis of emerging themes and a codebook was progressively elaborated. Trends in the data were identified by producing matrices allowing for

Table 1 Socio-demographic characteristics of respondents in Gelongba and Mandong Districts, Shan Special Region II, Myanmar

\begin{tabular}{|c|c|c|c|}
\hline & $\begin{array}{l}\text { All households } \\
\text { visited }(n=718)\end{array}$ & $\begin{array}{l}\text { Households with fever patients } \\
\text { in previous } 2 \text { weeks }(n=369)\end{array}$ & P-value \\
\hline \multicolumn{4}{|l|}{ Sex } \\
\hline Male & $478(66.6 \%)$ & $240(65.0 \%)$ & \\
\hline Female & $240(33.4 \%)$ & $129(35.0 \%)$ & 0.6615 \\
\hline \multicolumn{4}{|l|}{ Age (years) } \\
\hline$\leq 30$ & $405(56.4 \%)$ & $207(56.1 \%)$ & \\
\hline$>30$ & $313(43.6 \%)$ & $162(43.9 \%$ & 0.9739 \\
\hline \multicolumn{4}{|l|}{ Educational status } \\
\hline Illiterate & $701(97.6 \%)$ & $357(96.3 \%)$ & \\
\hline Read and write & $17(2.4 \%)$ & $12(3.3 \%)$ & 0.5105 \\
\hline \multicolumn{4}{|l|}{ Annual average income (US\$) } \\
\hline$\leq 100$ & $385(53.6 \%)$ & $191(51.8 \%)$ & 0.6048 \\
\hline $101-200$ & $254(35.4 \%)$ & $134(36.3 \%)$ & 0.8112 \\
\hline$>200$ & $79(11.0 \%)$ & $40(10.8 \%)$ & 0.9831 \\
\hline \multicolumn{4}{|l|}{ Family size of the household } \\
\hline$\leq 5$ & $376(52.4 \%)$ & $183(49.6 \%)$ & \\
\hline$>6$ & $342(47.6 \%)$ & $186(50.4 \%)$ & 0.4223 \\
\hline \multicolumn{4}{|l|}{ Residence } \\
\hline Altitude $<800 \mathrm{~m}$ & $148(20.6 \%)$ & $116(31.4 \%)$ & \\
\hline Altitude $\geq 800 \mathrm{~m}$ & $570(79.4 \%)$ & $253(68.6 \%)$ & 0.0001 \\
\hline \multicolumn{4}{|l|}{ Malaria knowledge } \\
\hline Knew mosquitoes caused malaria & $228(31.8 \%)$ & $114(30.9 \%)$ & 0.8256 \\
\hline Knew fever as symptom of malaria & $508(70.8 \%)$ & $261(70.7 \%)$ & 0.9494 \\
\hline Did not know correct malaria knowledge & $212(29.5 \%)$ & $92(24.9 \%)$ & 0.1268 \\
\hline \multicolumn{4}{|c|}{ Distance from health facilities or drug shops } \\
\hline$\leq 3 \mathrm{~km}$ & $159(22.1 \%)$ & $74(20.1 \%)$ & \\
\hline$>3 \mathrm{~km}$ & $559(77.9 \%)$ & $295(79.9 \%)$ & 0.4732 \\
\hline \multicolumn{4}{|l|}{ Family decision } \\
\hline Wife or co-decision & $139(19.4 \%)$ & $75(20.3 \%)$ & 0.7652 \\
\hline Husband & $545(75.9 \%)$ & $283(76.7 \%)$ & 0.8307 \\
\hline No respondence & $34(4.7 \%)$ & $11(3.0 \%)$ & 0.2247 \\
\hline \multicolumn{4}{|l|}{ Sex of fever patients } \\
\hline Male & - & $227(61.5 \%)$ & - \\
\hline Female & - & $142(38.5 \%)$ & - \\
\hline \multicolumn{4}{|l|}{ Age category of fever patients } \\
\hline$\leq 15$ & - & $41(11.1 \%)$ & - \\
\hline $16-50$ & - & $276(74.8 \%)$ & - \\
\hline$>50$ & - & $52(14.1 \%)$ & - \\
\hline
\end{tabular}


combination and comparison of information from the different key informants.

\section{Ethical approval}

According to the Helsinki Declaration, ethical approval for the study was granted by the Ethics Committees of Yunnan Institute of Parasitic Diseases, China. The purpose of the study was explained to the local health authority and the study participants and informed consent was obtained.

\section{Results}

\section{Sociodemographic characteristics of respondents}

A total of 718 households were visited and a total of 3,678 people lived in the households. The mean family size was 5.8 (range 1-13) persons per household. 369 heads of households with fever patients in previous two weeks were interviewed. Sociodemographic characteristics were similar $(\mathrm{P}>0.05)$ between households visited and households with fever patients, except resident altitude. This might be because people living at low altitude contract malaria more readily (Table 1 ). The mean age of respondents was $35.6(\mathrm{SD} \pm 13.5)$ years, $240(65.0 \%)$ were male. Most households mainly live on growing dry field rice, and a few households have a member working in rubber plantation. The mean age of the 36 key informants was 32.7 ( $\mathrm{SD} \pm 17.5$ ) years, and all 23 village heads were male, seven village health workers were male and five female.

Table 2 Malaria treatment-seeking behaviour of fever patients in previous two weeks in Gelongba and Mandong Districts, Shan Special Region II, Myanmar

\begin{tabular}{|c|c|c|}
\hline & Number & Percent $(95 \% \mathrm{Cl})$ \\
\hline \multicolumn{3}{|c|}{ Time between onset of illness and treatment sought } \\
\hline 24 hours & 118 & $32.0(27.2-37.0)$ \\
\hline $25-48$ hours & 24 & $6.50(4.2-9.5)$ \\
\hline$>48$ hours & 181 & $49.2(43.8-54.3)$ \\
\hline Never sought treatment & 46 & $12.5(9.3-16.3)$ \\
\hline \multicolumn{3}{|c|}{ Place where first advice and treatment sought } \\
\hline Drug peddlers & 178 & $48.2(43.0-53.5)$ \\
\hline Drug shops and market stalls & 79 & $21.4(17.3-26.0)$ \\
\hline Community health centre & 8 & $2.2(0.9-4.2)$ \\
\hline Village health workers & 31 & $8.4(5.8-11.7)$ \\
\hline Other source & 27 & $7.3(4.9-10.5)$ \\
\hline Staying home & 46 & $12.5(9.3-16.3)$ \\
\hline \multicolumn{3}{|l|}{ Methods of diagnosis received } \\
\hline Microscopy & 74 & $20.0(16.1-24.5)$ \\
\hline RDT & 30 & $8.1(5.6-11.4)$ \\
\hline Clinical (non laboratory-based) & 265 & $71.8(66.9-76.4)$ \\
\hline
\end{tabular}

\section{Treatment-seeking behaviours}

Overall $87.5 \%$ (323) of the febrile sought treatment; $32.0 \%$ (118) sought it within 24 hours, $6.5 \%$ (24) within 24-48 hours and $49.2 \%$ (181) after 48 hours. Of the 323 fever patients who sought treatment, $79.6 \%$ (257) went to the retail sector (drug peddlers, shops and market stalls); 8.4\% (31) sought from village health workers (the lowest level public health facility); $2.2 \%$ (eight) went to community health centres; $7.3 \%$ (27) sought advice or treatment from other sources such as a traditional healer, a friend or relative (Table 2). The proportion accessing the retail sector was statistically significantly higher than accessing the public sector $(\mathrm{P}<0.0001)$. Of the 46 who stayed at home, $73.9 \%$ (34) already had drugs in the house; $67.4 \%$ (31) sought help from supernatural spirit. The proportion of fever patients who received laboratory-based diagnosis was low (20.08\% for microscopy and $8.1 \%$ for RDT, respectively) (Table 2). Of 104 febrile who received laboratory-based diagnosis, 7.7\% (eight) received it at the community health centre and 92.3\% (96) in outreach service of NGOs. Of the 257 who sought treatment in the retail sector, 65.8\% (169) received under-dosed paraquin; $13.0 \%(42 / 323)$ took herbs and $3.4 \%(11 / 323)$ took only a febrifuge, such as paracetamol.

\section{Factors related to treatment-seeking}

The results from interviewing key informants, public health facilities and their service were very limited in Wa State. The central government of Myanmar only runs hospitals and clinics in main towns in Wa State; they hardly provide any health service at community level. The local government of special region had a community health centre $(\mathrm{CHC})$ in Gelongba. Despite there being six staff in the $\mathrm{CHC}$, none of the staff had professional training in health or medicine in formal school. The only available medical instruments were two stethoscopes and three thermometers. Anti-malarial drugs had been out of stock at the time of survey. This determined why medical sellers were the most accessible and widely used health resources. Most of the medical sellers did not know precise chloroquine doses for children and dosing information they gave was often inadequate, however the patients prefer their services because they satisfy their needs. For example, even if the retailers were aware that an oral therapy would be appropriate, they might sell injectable formulations if a client asked or they knew that patients believed injections to be more effective.

The results of multivariable logistic regression analysis showed that five variables were independently associated with delayed malaria treatment. Families with an average yearly income per person more than US\$200 were more likely to seek treatment for malaria within 24 hours. 
Households located more than $3 \mathrm{~km}$ from a health facility were more likely to delay seeking malaria treatment. Families, whose wives could make decisions or codecisions, were more likely to seek treatment in time. Families were more likely to seek treatment promptly if patients were male, and for children under 15 years old (Table 3).

\section{Discussion}

The health system's deficiencies play an important role in the performance of the case management strategy of global malaria control. The political divarication between central government and local government led to the national health system (NHS) not being able to effectively cover the Wa State. Since cease-fire between the central

Table 3 Variables associated with delay in malaria treatment-seeking behaviour for fever patients in Gelongba and Mandong Districts, Shan Special Region II, Myanmar

\begin{tabular}{|c|c|c|c|c|}
\hline & Treatment < 24hrs (\%) & Univariate OR (95\% CI) & Adjusted OR (95\% CI) & $P$ values \\
\hline \multicolumn{5}{|l|}{ Sex of respondents } \\
\hline Male $(n=240)$ & $76(31.8)$ & $0.96(0.59-1.56)$ & $0.89(0.44-1.89)$ & 0.936 \\
\hline Female $(n=129)$ & $42(32.4)$ & 1 & & \\
\hline \multicolumn{5}{|l|}{ Age of respondents } \\
\hline$\leq 30(n=207)$ & $66(32.1)$ & $0.99(0.62-1.58)$ & $0.96(0.37-2.06)$ & 0.955 \\
\hline$>30(n=162)$ & $52(31.9)$ & 1 & & \\
\hline \multicolumn{5}{|l|}{ Educational status } \\
\hline Illiterate $(n=357)$ & 107(31.4) & $0.43(0.12-1.54)$ & $0.56(0.11-1.68)$ & 0.345 \\
\hline Read and write $(\mathrm{n}=12)$ & $11(50.0)$ & 1 & & \\
\hline \multicolumn{5}{|c|}{ Average yearly income (USA) } \\
\hline$\leq 100(n=191)$ & $34(18.0)$ & $0.08(0.04-0.18)$ & $0.12(0.10-0.58)$ & 0 \\
\hline $101-200(n=134)$ & $52(38.5)$ & $0.24(0.10-0.53)$ & $0.26(0.17-0.79)$ & 0.002 \\
\hline$>200(n=44)$ & $32(72.6)$ & 1 & 1 & \\
\hline \multicolumn{5}{|c|}{ Family size of the household } \\
\hline$\leq 5(n=183)$ & $59(32.2)$ & $1.02(0.65-1.62)$ & $1.04(0.46-1.89)$ & 0.996 \\
\hline$>6(n=186)$ & $59(31.7)$ & 1 & 1 & \\
\hline \multicolumn{5}{|l|}{ Residence altitude } \\
\hline Altitude > 800 m (n=153) & $74(48.2)$ & $1.53(0.91-2.58)$ & $1.15(0.67-2.72)$ & 0.113 \\
\hline Altitude $\leq 800$ m (n=116) & $44(38.1)$ & 1 & & \\
\hline \multicolumn{5}{|l|}{ Knew malaria cause } \\
\hline Yes $(n=114)$ & $34(30.2)$ & $0.87(0.52-1.42)$ & $0.95(0.44-1.89)$ & 0.637 \\
\hline No $(n=255)$ & $84(32.8)$ & 1 & 1 & \\
\hline \multicolumn{5}{|l|}{ Knew malaria symptoms } \\
\hline Yes $(n=261)$ & $79(30.1)$ & $0.776(0.47-1.27)$ & $0.55(0.22-1.32)$ & 0.331 \\
\hline No $(n=108)$ & $39(36.4)$ & 1 & 1 & \\
\hline \multicolumn{5}{|c|}{ Distance from health facilities } \\
\hline$\leq 3 \mathrm{~km}(\mathrm{n}=74)$ & $44(59.8)$ & $4.38(2.49-7.74)$ & $2.03(1.26-6.07)$ & $<0.0001$ \\
\hline$>3 \mathrm{~km}(\mathrm{n}=295)$ & $74(25.0)$ & 1 & & \\
\hline \multicolumn{5}{|l|}{ Family decision } \\
\hline Wife or co-decision $(n=75)$ & $47(62.3)$ & $5.01(2.83-8.92)$ & $2.65(1.53-7.18)$ & $<0.0001$ \\
\hline Husband $(n=283)$ & $71(25.2)$ & 1 & 1 & \\
\hline \multicolumn{5}{|l|}{ Sex of fever patients } \\
\hline Male $(n=227)$ & $101(44.4)$ & $6.79(3.62-12.9)$ & $3.36(1.99-13.21)$ & $<0.0001$ \\
\hline Female $(n=142)$ & $15(10.4)$ & 1 & 1 & \\
\hline \multicolumn{5}{|c|}{ Age category of fever patients } \\
\hline$\leq 15(n=41)$ & $41(87.2)$ & 28.7(8.57-102.02) & $4.24(1.89-99.47)$ & $<0.0001$ \\
\hline $16-50(n=276)$ & $67(24.8)$ & $1.39(0.63-3.13)$ & $0.71(0.24-2.56)$ & 0.492 \\
\hline$>50(n=52)$ & $10(18.9)$ & 1 & 1 & \\
\hline
\end{tabular}


government and local government in 1988, the central government has established three hospitals in main towns and the local government was trying to establish a health service network but is short of investment in human resources and basic facilities, and some international NGOs were running some health programmes, however all three efforts have not established an effective public health service system.

A large proportion of febrile patients sought advice or treatment, however most of them sought treatment from medical sellers, so a high proportion of the febrile was only diagnosed by clinical symptoms for malaria, and most of the microscopy or RDT were given by outreach service of NGOs. In the neighbouring region (Yunnan Province of China), $82 \%$ of malaria patients chose township community hospitals first [6]. The literature regarding treatment seeking in Myanmar and other countries of Greater Mekong subregion is rare. The situation seems similar that in sub-Saharan Africa; medicine sellers are widely used for fever and malaria treatment [14]. Despite the drug seller market being extremely informal, it is the most available and stable provider. The Roll Back Malaria (RBM) Partnership had set a target for $80 \%$ to receive appropriate treatment within 24 hours by 2010 [15]. However, this study found it was far away from that target. WHO now advocates strategies to improve home-based management of malaria, with retailer interventions being seen as one possible channel $[16,17]$. At present, this could be one of strategies addressing timely and appropriate treatment of malaria for the Wa people.

Wa State is an endemic area of falciparum malaria. Patients should seek treatment within 24 hours, however less than one third of patients to do so. Of $12.5 \%$ (46/ 369) of febrile patients who never sought treatment outside the home, $67.4 \%$ (31/46) of them sought help from supernatural spirit. In the culture of Wa ethnics, people believe in everything has its soul, so they might seek help from spirit when they are ill. A study done in Burkina Faso showed that literacy level of the heads of the households was the main factor to bring children within 24 hours to the health facility for the treatment of malaria [18]. In this study, 96.7\% (357/369) of respondents were illiterate. Studies carried out in Ethiopia [19] and southern Ghana [20] showed that knowledge of respondents is not associated with malaria treatment-seeking [19]. Knowledge itself is not equal to behaviour. People's perception, knowledge and awareness, assured material supply and enabling environment are necessary for behaviour development [21]. Family income and distances from a health facility can solve accessibility in economics and geography respectively, so the two factors are associated with treatment seeking in the study. In Wa tradition, men are usually more respectable and powerful than women [6]; on the other hand, mothers are usually child carers and housework undertakers, so wife or co-decision can increase timely treatment seeking, and male patients and children are more likely to be assisted in seeking treatment.

In the study design, the hypothesis is no difference in treatment-seeking between households in which there was someone with fever in the last two weeks compared to households without. In order to reduce recall bias, the households without fever in the last two weeks were just interviewed for socio-demographic characteristics, but for treatment-seeking and other related factors. In true-life, there may be differences in fever frequency and treatment-seeking pattern between the two household groups. This limitation may affect the results of the study. However the population of the two districts is estimated at 18, 940, but 718 households with $19.4 \%$ (3, 678 ) of the total population was visited. This can reduce sample bias caused by the difference.

\section{Conclusion}

Malaria treatment-seeking behaviour is not effective, and factors affecting this include health service systems, social and cultural features in the Wa State of Myanmar.

\section{Competing interests}

The authors declare that they have no competing interests.

\section{Authors' contributions}

J-WX, Q-ZX and HL designed the study and developed the protocol, analyzed and interpreted the data. HL supervised the field survey. Q-ZX, Y-R $\mathrm{Z}$ and $\mathrm{HL}$ conducted $\mathrm{HH}$ s survey, SDI, health facility visits and the outlet survey, and entered the data. J-WX and Q-ZX wrote the first draft of the paper. All authors read and approved the final manuscript.

\section{Acknowledgements}

We thank the fifth grant to China of the Global Fund to fight AIDS, Tuberculosis and Malaria (GFATM) for financial sponsor. We are grateful to Dr Chun-Fu Li, Dr Xing-Liang Li and Ren-Hua Nie from Yunnan Institute of Parasitic Disease (YIPD) involvement of field work. We thank participants and local health sector for their collaboration in field survey. The opinions expressed are those of the authors and do not necessarily reflect those of YIPD and GFATM.

\section{Author details}

${ }^{1}$ Yunan Institute of Parasitic Diseases, Puer 665000, China. ${ }^{2}$ People's Hospital of Taikang County, Henan Province, China. ${ }^{3}$ Mengmao County Hospital, Shan Special Region II, Myanmar.

Received: 3 August 2012 Accepted: 8 December 2012

Published: 14 December 2012

\section{References}

. World Health Organization: World malaria report: 2011. Geneva: WHO; 2011

2. Sachs J, Malaney P: The economic and social burden of malaria. Nature 2002, 415:680-685.

3. WHO: Global Malaria Control and Elimination: report of a technical review, World Health Organization Global Malaria Programme. Geneva: WHO; 2008

4. Wangroongsarb P, Satimai W, Khamsiriwatchara A, Thwing J, Eliades JM, Kaewkungwal J, Delacollette C: Respondent-driven sampling on the Thailand-Cambodia border. II. Knowledge, perception, practice and treatment-seeking behaviour of migrants in malaria endemic zones. Malar J 2011, 10:117 
5. Yeung S, Van Damme W, Socheat D, White NJ, Mills A: Cost of increasing access to artemisinin combination therapy: the Cambodian experience. Malar J 2018, 7:84

6. Xu JW: Community-based malaria control for ethnic minority groups: malaria control progress of a Wa ethnic community at China-Myanmar border. World J Inf 2009, 9:218-223.

7. Liu H, Nie RH, Li CF, Sun YH, Li GS: Active detection of malaria cases in Myanmar Wa ethnical villages of China-Myanmar border (abstract in English). Parasitol Infect Dis 2009, 7:6-8.

8. Xu JW, Xia M, Petlueng P, Tao H, Zhong YC, Wu XH, Liu SM, Wen ZD, Liu H: Current situation, affordability and obstacles on treatment-seeking of Wa ethnic in Ximeng, Yunnan. China Trop Med 2004, 4:937-939.

9. Xu JW, Xia M, Petlueng P, Tao H, Zhong YC, Wu XH, Liu SM, Wen ZD, Liu H: Current situation, attitudes and scaling up obstacles toward usage of bednets in Wa ethnic. China Trop Med 2004, 4:319-321.

10. Henderson RH, Sundaresan T: Cluster sampling to assess immunization coverage: a review of experience with a simplified sampling method. Bull World Health Organ 1982, 60:253-260.

11. Smith L, Bruce J, Gueye L, Helou A, Diallo R, Gueye B, Jones C, Webster J: From fever to anti-malarial: the treatment-seeking process in rural Senegal. Malar J 2010, 9:333.

12. Wen L, Lieber $E$, Wan D, Hong YH: A qualitative study about selfmedication in the community among market vendors in Fuzhou, China. Health Soc Care Community 2011, 19:504-13.

13. Lauritsen J: EpiData Data Entry, Data management and basic Statistical Analysis System Version 3.1. Odense, Denmark: EpiData Association; 2000

14. Goodman C, Brieger W, Unwin A, Mills A, Meek S, Greer M: Medicine sellers and malaria treatment in sub-saharan africa. AmJTrop Med Hyg 2007, 77(Suppl):203-218.

15. WHO: RBM Global Strategic Plan: Roll Back Malaria 2005-2015. Geneva: Roll Back Malaria Partnership, World Health Organization; 2005.

16. WHO: Scaling up home-based management of malaria. Geneva: Roll Back Malaria Department/UNICEF/UNDP/World Bank/TDR WHO/HTM/MAL/ 2004.1096; 2004

17. WHO: The Roll Back Malaria Strategy for Improving Access to Treatment through Home Management. Geneva: WHO/HTM/MAL/2005.1101; 2005.

18. Tipke M, Louis RV, Yé M: Access to malaria treatment in young children of rural Burkina Faso. Malar J 2009, 8:266.

19. Getahun A, Deribe $K$, Aare Deribew A: Determinants of delay in malaria treatment seeking behaviour for under-five children in south-west Ethiopia: a case control study. Malar J 2010, 9:320.

20. Ahorlu CK, Koram KA, Ahorlu C, de Savigny D, Weiss MG: Socio-cultural determinants of treatment delay for childhood malaria in southern Ghana. Trop Med Int Health 2006, 11:1022-103.

21. Xu JW, Wu XH, WEI C, Petlueng P, Tao H, Lin H, Xia: A pilot study on strengthening malaria control for ethnic minorities (abstract in English). Chin J Vector Biol Control 2010, 21:527-530.

doi:10.1186/1475-2875-11-417

Cite this article as: Xu et al: Malaria treatment-seeking behaviour and related factors of Wa ethnic minority in Myanmar: a cross-sectional study. Malaria Journal 2012 11:417.

\section{Submit your next manuscript to BioMed Central and take full advantage of:}

- Convenient online submission

- Thorough peer review

- No space constraints or color figure charges

- Immediate publication on acceptance

- Inclusion in PubMed, CAS, Scopus and Google Scholar

- Research which is freely available for redistribution 